\title{
Der Blattlose Widerbart (Epipogium aphyllum), Orchidee des Jahres 2014
}

\author{
Kurt Baumann
}

\begin{abstract}
The ghost orchid (Epipogium aphyllum) is a myco-heterotrophic orchid without chlorophyll. In Germany it is a rare species. It is orchid of the year 2014. Biology, ecology and morphology are outlined.
\end{abstract}

Zusammenfassung

Der Blattlose Widerbart (Epipgogium aphyllum) ist eine myko-heterotrophe Orchidee ohne Chlorophyll. Die seltene Art wurde 2014 zur Orchidee des Jahres gekürt. Ihre Biologie, Ökologie und Morphologie werden herausgestellt.

\section{Lebensweise}

Mit dem Blattlosen Widerbart wurde eine in Deutschland sehr seltene und in mancherlei Hinsicht (Lebensweise, Blütenbau) sich von den anderen einheimischen Orchideen unterscheidende Art zur 25. Orchidee des Jahres gewählt. Entsprechend seiner Seltenheit hat der Widerbart wenige Volksnamen. Der Name Widerbart hat sich gegenüber den anderen durchgesetzt und wird allgemein gebraucht. Andere Namen waren Ohnblatt, Bananen-Orchis (nach dem Duft) und wegen der eigenartigen Lippenstellung Oberkinn, Bartläppchen, Bartständel und Haube. Nach Mersel (2013) sind die englische Bezeichnung ghost-orchid (Geister-Orchidee) und die schwedische skogsfru (Waldfrau) zwei treffende Namen für diese eigenartige Orchidee.

Der wissenschaftliche Name Epipogium aphyllum deutet an, dass der Blattlose Widerbart außer wenigen kleinen, farblosen Schuppenblättern keine weiteren Blätter trägt (griech. aphyllum = blattlos). Zudem enthält er kein Chlorophyll. Dementsprechend ist er zu der üblichen autotrophen (selbsternährenden) Lebensweise der grünen Pflanzen und der damit verbundenen Bildung von Zucker nicht fähig. Widerbart und die anderen einheimischen chlorophyllfreien Orchideen (Dingel, Vogelnestwurz, Korallenwurz) werden in den allermeisten Orchideenbüchern (einschließlich des Standardwerks der AHO 2005, auch Kretzschmar 2008) als Moderpflanzen bzw. Saprophyten bezeichnet. Sie leben angeblich vom Humus. Dies ist aber sachlich falsch, wie schon Meysel (2013) in seinem ausführlichen Überblick richtigstellt. Sap- rophyten (griech. Fäulnispflanzen) sind heterotrophe (von anderen ernährend) Lebewesen, die von totem organischen Substrat leben, das sie mit Hilfe ihrer Enzyme abbauen und zersetzen und so die lebensnotwendigen Verbindungen und Energieträger gewinnen. Dies erledigen Pilze und Bakterien. Nach Bresinsky et al. (2008) gibt es keine höhere Pflanze, also auch keine Orchidee, die saprophytisch lebt. Ihnen fehlen die notwendigen Enzyme.

Auch die ebenso oft gebrauchte Bezeichnung Symbiose für die von den Orchideen eingegangene Lebensgemeinschaft mit Pilzen ist nicht korrekt. Alle Orchideen benötigen ein Zusammenleben mit Pilzen zur Keimung bis hin zur Entwicklung des ersten grünen Blattes, da die Samen keine Nährstoffe enthalten (SElosse 2007, Roy 2012). Die Pilzfäden dringen in die Zellen des Embryos ein, werden abgetötet und abgebaut. Die Orchidee lebt von den gewonnenen Stoffen. Bei den sogenannten Moderorchideen bleibt diese Abhängigkeit das ganze Leben lang bestehen. Eine Symbiose im engeren Sinne ist das aber nicht, denn darunter versteht man ein Zusammenleben mit wechselseitigem Vorteil. Dies gilt z. B. für die Mykorrhiza (Pilzwurzel) bei Bäumen, bei denen der Pilz Wasser und Salze liefert, der Baum dem Pilz Zucker. Es gibt keine wissenschaftliche Arbeit, in der nachgewiesen wird, dass Stoffe von den Moderorchideen auf den Pilz übertragen werden. Untersuchungen (allerdings nicht am Widerbart) führten zum Ergebnis, dass die Orchideen $\mathrm{Zu}$ cker von den Bäumen erhalten, mit denen die Pilze in Kontakt stehen (Selosse 2007). Deshalb kann man das Zusammenleben von Or- 
chidee und Pilz nur als eine einseitige Angelegenheit ansehen, d. h. die Orchidee schmarotzt auf dem Pilz (Buttler 1986, Vöth 1999, Meysel 2013). Sie bezieht von dem Pilz alle notwendigen Nutz- und Wirkstoffe. Von manchen Autoren (Presser 2002, Rysy 2014) wird die Lebensweise der Moderorchideen als mykotroph oder mykoheterotroph (pilzernährt) bezeichnet. Das ist eine doppeldeutige Bezeichnung, denn sie umfasst sowohl die echten Pilzsymbiosen u. a. bei den Bäumen als auch den Parasitismus der Orchideen bei der Keimung und den Moderorchideen.

Mit modernen Untersuchungsmethoden wurde inzwischen auch festgestellt, welche Pilze die Lebensgemeinschaft mit den Orchideen eingehen. Es sind ganz unterschiedliche Arten. Beim Widerbart handelt es sich in $75 \%$ der untersuchten Fälle um Pilze der Gattung Inocybe, zu der u. a. der sehr giftige Risspilz gehört (Roy et al. 2009). Bei den restlichen $25 \%$ treten verschiedene Pilze auf, u. a. Pilze der Gattung Hebeloma (Fälblinge).

\section{Bau der Pflanze}

Der Widerbart entspringt einem Rhizom, das knollig korallen- oder geweihartig verzweigt ist (REINHARD et al. 1991). Es trägt schuppenartige Niederblätter, hat aber keine Wurzeln. Die vorjährigen dunkelbraunen Glieder bilden bauchige Bulbillen, aus denen Blütenstängel entstehen. Nach der Blütezeit sterben die Glieder ab. Inzwischen sind neue, hellgefärbte Glieder herangewachsen, die im Herbst neue Bulbillen treiben und überwintern (KüNKELE \& BAUMANN 1998). Das Rhizom gedeiht nicht in mineralischem Erdboden, sondern in Mulm (Vöтн 1999). Dabei handelt es sich um ein Lockersediment aus organischem Material, das zum größten Teil aus Bakterien, Mineralien, Pflanzenresten und Stoffwechselendprodukten besteht. Das Rhizom bildet zahlreiche lange dünne (fadenförmige), mit kleinen Schuppenblättern besetzte Ausläufer. In feuchtem Waldboden kommt es zur Streckung der Internodi-

Abb. 1: Stattliche Widerbart-Gruppe.

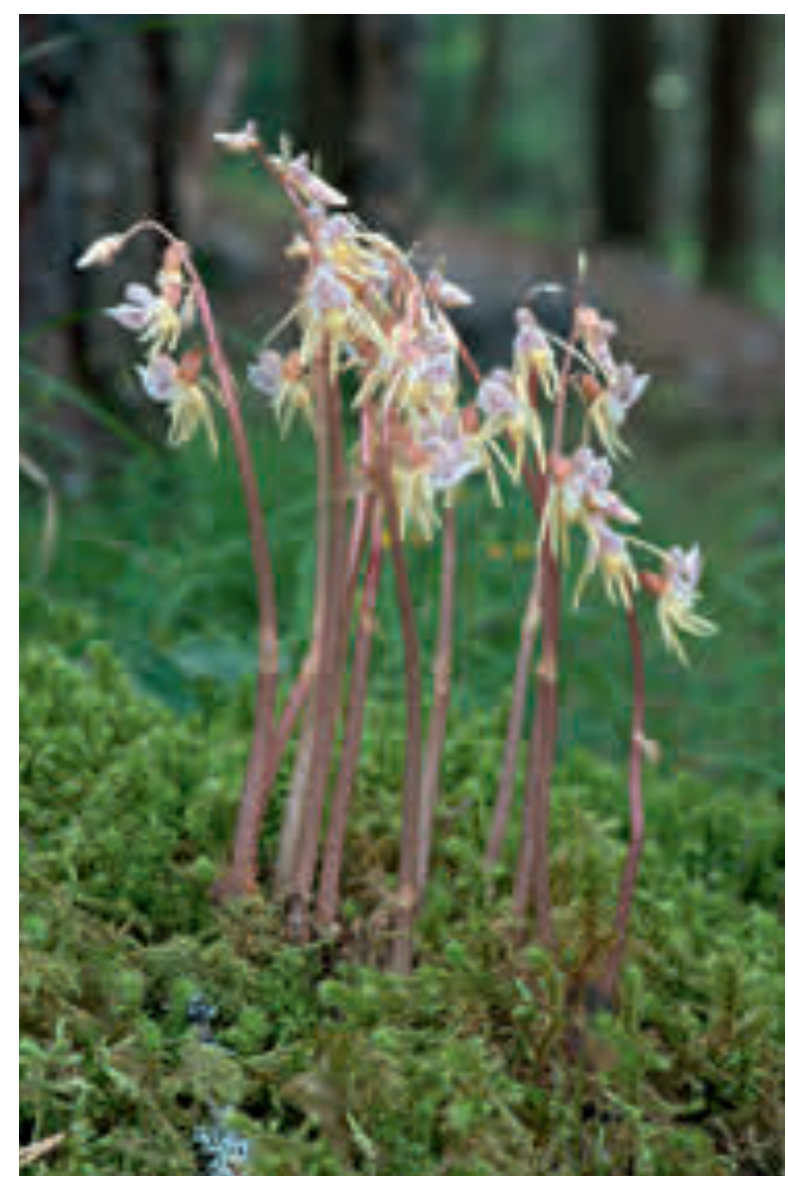

en. Da die Schuppenblätter dann in mehr oder weniger regelmäßigen Abständen stehen, sehen sie wie Perlenschnüre aus (Reinecke 1998). In den Achseln der Schuppenblätter entstehen knollenartige Anschwellungen, aus denen sich neue Rhizome bilden, die sich ablösen und verschwemmt werden können (FüLLER 1967).

Die zur vegetativen Vermehrung dienenden Ausläufer des Widerbarts haben nur eine geringe Durchdringungskraft. Bodenverdichtung durch Wildwechsel, menschliche Trampelpfade oder gar schwere Waldbaumaschinen sind ein unüberwindliches Hindernis. Es kommt zu Knäuelungen der Ausläufer. Reinecke \& Rietdorf (1998) führen darauf das truppweise Auftreten des Widerbarts zurück, mit bis zu 20 Pflanzen. Andere Autoren nehmen als Ursache ein Rhizom an, das reich an Seitensprossen ist, sodass es zum gebüschelten Zusammenstehen der Pflanzen kommt.

Anfang Juli durchbrechen die Blütentriebe den Boden und strecken sich. Sie werden $5-$ $30 \mathrm{~cm}$ hoch. Der Stängel ist an der Basis kuge- 
lig verdickt, durchscheinend, röhrig, kahl, blassgelb und rotbräunlich überlaufen. Er trägt keine Blätter, lediglich 1-4 stängelumfassende, spitze Schuppen. Der Stängel ist saftig und wird allein vom Wasserdruck in der Zelle aufrecht gehalten, da kein ausreichendes Festigungsgewebe vorhanden ist (MEYSEL 2013).

Die Blütezeit des Blattlosen Widerbarts dauert, je nach Witterung und Lage, von Anfang oder Mitte Juli bis Ende August. Der Blütenstand ist eine $1,5-6 \mathrm{~cm}$ lange Traube. Er umfasst 1 - 6 (10) hängende, locker angeordnete, große Blüten. Sie stehen in den Achseln häutiger, bräunlicher, lineal-lanzettlicher, 7-11 mm langer, abwärts gerichteter Tragblätter (BAUMANN \& KÜNKele 1982). Ein wichtiger Unterschied zu anderen Orchideen besteht darin, dass die Drehung des Fruchtknotens um 180 unterbleibt. Üblicherweise erreichen die Orchideen aufgrund dieser Drehung, dass das größte Blütenblatt, die Lippe, nach unten gerichtet ist und somit als Landeplatz für die Bestäuber fungieren kann. Der 4-10 mm lange, ovale Fruchtknoten des Widerbarts ist langgestielt und waagerecht bis abwärts gebogen.

Beim Widerbart ist also die Lippe nach oben gerichtet. Darauf nimmt der wissenschaftliche Gattungsname Bezug (griech. epi = aufwärts; griech pogon $=$ Bart, frühere Bezeichnung für die Lippe der Orchideen). Die weißliche Lippe ist dreilappig. Ihre beiden kürzeren Seitenlappen sind abwärts gerichtet. Der aufwärts gerichtete Mittellappen ist breit oval bis herzförmig, 9-12 mm lang und 9-10 $\mathrm{mm}$ breit). Er ist zugespitzt und an den Rändern gekerbt. Der Länge nach wird er von 4-6 gekräuselten Leisten durchzogen, die mit roten Papillen besetzt sind.

Die fünf restlichen Blütenblätter sind abwärts gerichtet. Sie sind gelblichgrün bis rahmfarben gefärbt, alle mit rund $17 \mathrm{~mm}$ fast gleich lang und rinnig eingerollt. Sie hängen frei und locker im Halbkreis. Der sackartige, stumpfe Sporn ist aufwärts gerichtet und gebogen. Er enthält keinen oder bestenfalls sehr wenig Nektar.

Das Säulchen ist halb so lang wie die Blütenblätter und ebenfalls abwärts gerichtet. Von den meisten Autoren wird eine Selbstbestäubung ausgeschlossen. Die beiden Pollinien sind mit langen, bandförmigen Stielchen versehen. Sie sind mit einem herzförmigen Klebkörper verbunden.

Die Blüten des Widerbarts duften schwach nach reifen Bananen. Von manchen wird der Duft als vanilleartig bezeichnet. Er ist ein Mittel zur Anlockung von Bestäubern, allerdings ist die Bestäubung nicht sehr effektiv, denn der Fruchtansatz ist mit nur $4 \%$ sehr gering. Wegen seines Standorts im schattigen Wald und seiner Seltenheit gab es lange Zeit keine Beobachtungen über Bestäubungen. Man nahm deshalb an, es käme zu Bestäubung und Befruchtung vor Beginn des Aufblühens in der aufrecht stehenden Knospe (Vöтн 1999). Wespen wurden als Bestäuber angenommen, aber es gab keine Beobachtungen (Ано 2005). Inzwischen ist nachgewiesen, dass verschiedene HummelArten die gelegentlichen Bestäuber sind und dass beim Widerbart keine Autogamie vorliegt (Claessens 2012).

Bereits während der Blütezeit reifen die Samen, sodass unten am Blütenstand Früchte hängen, während an der Spitze noch Blüten offen sind. Die runden, langgestielten, dicken, hängenden Früchte sind 5-20 mm lang und 8-10 mm breit. Die Samen sind nur 0,19-0,3 $\mathrm{mm}$ lang und $0,16-0,22 \mathrm{~mm}$ breit. Sie enthalten keine Reservestoffe. Nach vier Wochen sind die Früchte längstens reif und die Samen ausgestreut; die Pflanze ist dann meist bereits eingezogen und nicht mehr zu sehen. Diese kurze Erscheinungszeit und der Wuchsort, der botanischen Kartierern wenig bietet, sind Gründe, die Pflanze nicht zu finden. Außerdem kommt sie nicht jedes Jahr zum Blühen. Es können Jahre, sogar Jahrzehnte zwischen zwei Blühvorgängen liegen. Die Ursachen für die Stängelbildung sind nicht bekannt. Möglicherweise sind ausreichende Regenfälle im Frühjahr und Frühsommer eine Voraussetzung. Presser (2002) nennt auch schneereiche Winter als eine mögliche Vorbedingung.

\section{3. Ökologie und Verbreitung}

Im Gegensatz zu anderen Orchideen wächst der Blattlose Widerbart als Schattenpflanze im dunklen Wald. Da er kein Chlorophyll enthält, 
benötigt er kein Sonnenlicht. Er kommt nicht nur im Kalk-Buchenwald vor, sondern auch in Nadelbaumforsten wie in Fichtenwäldern (der berühmte Standort auf der Baar bei Hüfingen), Tannenwäldern und entsprechenden Mischwäldern mit Buchen. Selten findet man ihn in Talmulden und Trichtern, wo Kaltluftseen ihm das notwendige feuchte Mikroklima schaffen. Deshalb wächst er auch an Waldbächen und in Quellgebieten (Presser 2002).

Der Widerbart bevorzugt frische, nährstoffund basenreiche, schwach saure bis neutrale Böden. Sie sollten im Hochsommer nicht austrocknen. Er wächst gern auf mit Mulm oder Rohhumus angereicherten und mit Laubstreu bedeckten Waldböden. Die Wuchsorte sind häufig frei von Begleitflora oder nur mit niedrig bleibenden Pflanzen (Moosen u. a.) bewachsen. Er ist nicht konkurrenzfähig gegenüber den nach Aufforstung aufkommenden Pflanzen (VöтH 1999).

Seine Vorkommen erstrecken sich in Europa bis $1900 \mathrm{~m}$ Höhe, in Deutschland nur bis $1500 \mathrm{~m}$. Im Himalaya-Gebiet steigt er bis $4000 \mathrm{~m}$ hoch. Aber auch in Deutschland liegen seine Fundpunkte häufig oberhalb von $700 \mathrm{~m}$. Der Blattlose Widerbart ist eine eurasiatische Pflanze. Seine zerstreuten und unregelmäßigen Vorkommen erstrecken sich von Südengland (zwei Populationen) bis zum Pazifik (Kamtschatka, Sachalin, Japan). In Europa fehlt er in den mediterranen und kontinentalen (ungarische Tiefebene) Gebieten, aber auch in Portugal, Belgien und den Niederlanden. So findet man ihn von Nordspanien bis zum Balkan und im Norden bis nach Skandinavien (Baumann \& Künkele 1982, Meysel 2013). Die Vorkommen erstrecken sich ostwärts zum Kaukasus und durch das temperierte Asien bis Mandschurei und Korea.

In Deutschland ist er sehr lückenhaft verbreitet. So fehlt er in Norddeutschland weitgehend, im Rheinland, am Main und an der Donau (Ausnahme: Donau-Oberlauf) sowie in

Abb. 2 (oben): Ausschnitt aus dem Blütenstand.

Abb. 3 (unten): Makroaufnahme einer Einzelblüte.
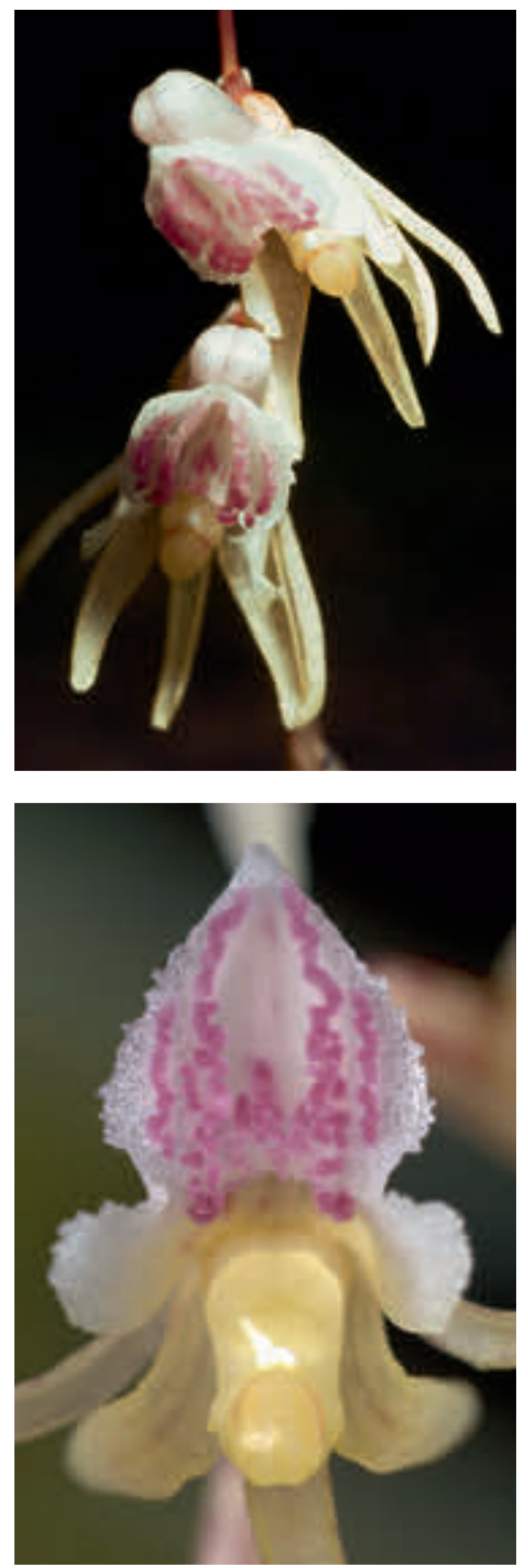


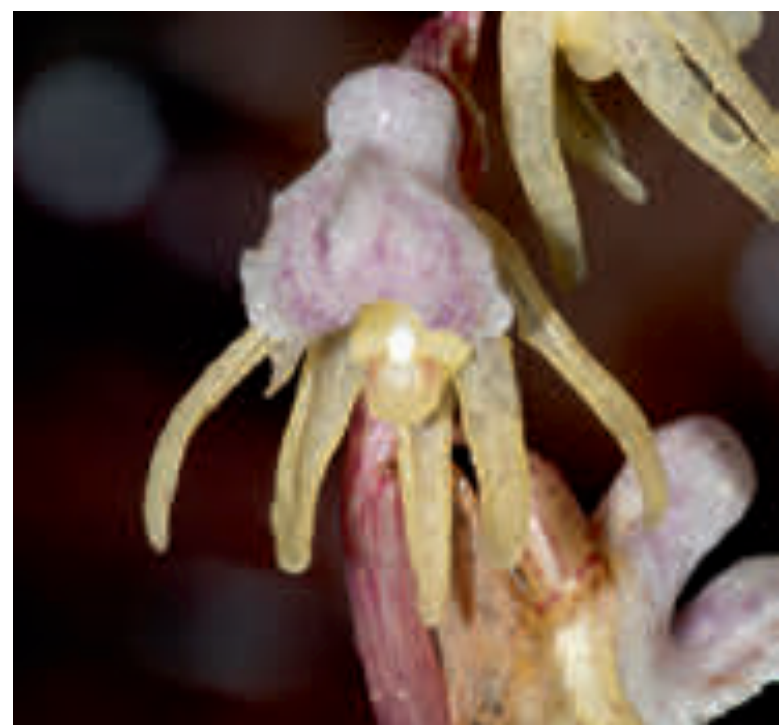

den östlichen Bundesländern. Die meisten Vorkommen liegen im Alpengebiet, in der Schwäbischen Alb und in der Mitte Deutschlands. Auch die hessischen Fundpunkte (frühere, inzwischen erloschene bzw. nicht mehr bestätigte, und wenige noch vorhandene) liegen im Norden des Bundeslandes (u. a. bei Korbach). Lediglich eine Stelle ist seit 2006 aus den Lahnbergen bei Marburg, also in Mittelhessen, bekannt (Ludwig 2007). Dem Vorkommen entsprechend ist der Widerbart in den meisten „Roten Listen“ der Bundesländer als stark gefährdet eingestuft. Lediglich in Baden-Württemberg gilt er nur als potenziell gefährdet. In Schleswig-Holstein ist er verschollen.

Der Widerbart war schon immer eine seltene Pflanze. Er ist in 544 Messtischblatt-Vierteln des ganzen Bundesgebietes gefunden worden (Aно 2005). Das sind nicht ganz 6\% aller deutschen Messtischblatt-Viertel. Nach 1950 wurde der Widerbart nur noch in 94 Quadranten nachgewiesen, was einem Rückgang von über $82 \%$ entspricht. Bei anderen Wald-Orchideen treten viel kleinere Rückgänge auf. Es wird vermutet, dass die Veränderung des Kleinklimas durch Aufforstung oder das Ausbleiben der natürlichen Walddynamik Ursachen für den Rückgang sein könnten. Es gibt eine Empfehlung, an aktuellen Standorten auf forstwirtschaftliche Maßnahmen mit bodenverdichtenden Maschinen und Kahlschlag zu verzichten. Wichtig scheint ein konservierender Schutz des
Habitats zu sein, also ein störungsfreier Wald (Meysel 2013). Andererseits gibt es aber auch Berichte, dass der Widerbart in jungen Fichtenschonungen gedeiht.

\section{Literatur}

Arbeitskreis heimische Orchideen, AHO (Hrsg.) 2005: Die Orchideen Deutschlands. - Uhlstädt-Kirchhasel. Baumann, H. \& Künkele, S. 1982: Die wildwachsenden Orchideen Europas. - Stuttgart.

Baumann, H., Künkele, S. \& Lorenz, R. 2006: Die Orchideen Europas. - Stuttgart.

Bresinsky, A., Körner, C., Kadereit, J., Neuhaus, G. \& Sonnewald, U. 2008: STrasburger, Lehrbuch der Botanik, 36. Aufl. - Heidelberg.

Buttler, K. P. 1986: Orchideen. - München. Claessens, J. \& Kleynen, J. 2012: Bestäubung europäischer Orchideen. - Bericht AHO 29, Beiheft 8: 14-32. Füller, F. 1967: Limodorum, Epipogium, Neottia, Corallorhiza. Die Orchideen Deutschlands, 7. Teil. Neue Brehm-Bücherei Bd. 385. - Wittenberg. Kretzschmar, H. 2008: Die Orchideen Deutschlands und angrenzender Länder. - Wiebelsheim.

Künkele, S., Baumann, H. 1998: Orchidaceae. In Sebald,O., Philippi, G. \& Seybold, S.: Die Farn- und Blütenpflanzen Baden-Württembergs. Bd.8. - Stuttgart. LudwIG, W. 2007:Über Epipogium aphyllum SW.:

$\mathrm{Zu}$ den Fundorten in Hessen. Hess. Flor. Briefe 56: 17-23. Meysel, F. 2013: Die Orchidee des Jahres 2014: Der Blattlose Widerbart (Epipogium aphyllum), ein Überblick. - Berichte AHO 30: 6-51.

Presser, H. 2002: Orchideen. 2. Aufl.- Hamburg. Reinecke, D. \& Rietdorf K. 1998: Bemerkungen zu Epipogium aphyllum in Südbaden. - Berichte AHO 15: 52-62.

Reinhard, H. R., Gölz, P., Peter, R. \& Wildermuth, H. 1991: Die Orchideen der Schweiz und angrenzender Gebiete. - Egg.

Roy, M, Takahiro Yagame, Masahide Yamato, Koji Iwase, Heinz, C., Faccio, A., bonfante, P \& Selosse, M.- A. 2009: Ectomycorrhizal Inocybe species associate with the mycoheterotrophic orchid Epipogium aphyllum. - Ann. Bot. 104: 595-610.

Roy, M. \& Selosse, M. 2012: Orchideen, die Pilze essen. - Berichte AHO 29, Beiheft 8: 143-159.

Rysy,W. 2014: Die Orchidee des Jahres 2014, Epipogium aphyllum, der Blattlose Widerbart.- Die Orchidee 65: 90-93.

Selosse, M. \& Guillaumin, J. 2007: Vom Keimstadium zur adulten Pflanze: Die symbiontischen Pilze der Orchideen. - Jahresber. Naturwiss. Ver. Wuppertal 60: 253-273.

Vöтн, W. 1999: Lebensgeschichte und Bestäuber der Orchideen am Beispiel Niederösterreichs. - Stapfia 65:1-259.

Abb. 4: Blüte des Widerbartes mit heller, aufrecht orientierrer Lippe. 